\title{
Association between socioeconomic status, sex, and age at death from cystic fibrosis in England and Wales (1959 to 2008): cross sectional study
}

\begin{abstract}
Objective To determine the trend in the association between socioeconomic status and sex and median age at death from cystic fibrosis in England and Wales, over the past 50 years.

Design Series of annual cross sectional studies of all registered deaths with a diagnosis of cystic fibrosis in England and Wales, from 1959 to 2008.

Methods We obtained national mortality data for cystic fibrosis from the Office for National Statistics. From 1959 to 2000, the Registrar General's Social Class coded socioeconomic status as manual or non-manual. From 2001 onwards, the National Statistics Socioeconomic Classification was implemented and socioeconomic status was split into three groups: professional and managerial, intermediate, and routine and manual. We calculated median age at death for every study year. We calculated the effects of sex and socioeconomic status on the odds of death above the median age at death for every study decade using logistic regression.

Results From 1959 to 2008, 6750 deaths were attributed to cystic fibrosis in England and Wales. Males were more likely to die above the annual median age at death than females (from 1959 to 1999, adjusted odds ratio for socioeconomic status $1.28,95 \%$ confidence intervals 1.13 to 1.45 ; from 2000 to $2008,1.57,1.18$ to 2.08 ). Individuals in the highest socioeconomic class were also more likely to die above the median age of death than those in the lowest socioeconomic class (from 1959 to 2000 , adjusted odds ratio for sex 2.50, 2.16 to 2.90; from 2001 to 2008 , $1.89,1.20$ to 2.97$)$.
\end{abstract}

Conclusions Socioeconomic status and sex remain strong determinants of survival from cystic fibrosis in England and Wales, and the magnitude of these effects does not appear to have substantially reduced over time.

\section{Introduction}

Over the past 50 years, survival in individuals with cystic fibrosis has improved greatly, with the median age at death rising from 6 months in $1959^{1}$ to 27 years in $2008 .{ }^{2}$ For individuals with cystic fibrosis born in 2000 , the median age of survival is predicted to approach 50 years. ${ }^{3-5}$ Improved survival has been attributed to multiple factors including early diagnosis, ${ }^{67}$ improvements in nutrition, ${ }^{8}$ infection control,,${ }^{9-11}$ nebulised mucolytics, ${ }^{12}$ and antibiotic treatment. ${ }^{13}{ }^{14}$ Factors associated with early death include the $\delta$ F508 mutation, ${ }^{15}$ pancreatic insufficiency, ${ }^{16}{ }^{17}$ low body mass index, ${ }^{18}$ early acquisition of Pseudomonas aeruginosa,${ }^{19-21}$ low socioeconomic status, ${ }^{122}{ }^{23}$ and female sex. ${ }^{24-27}$

High socioeconomic status was identified as a marker of good prognosis in cystic fibrosis over 20 years ago, when children with cystic fibrosis from manual socioeconomic groups in England and Wales were found to be nearly three times more likely to die below the annual median age at death than those from non-manual socioeconomic groups. ${ }^{1}$ Schechter and colleagues reported a similar effect in Medicaid patients in the United States, ${ }^{22}$ and other reports have shown reduced survival in patients living in postal code areas with below median incomes. ${ }^{23}$

The association between female sex and impaired prognosis in cystic fibrosis has also been well described, ${ }^{24}{ }^{25}$ with a median difference of 3.1 years in one study. ${ }^{26} \mathrm{~A}$ Canadian study reported that females had more than twice the two year risk of death than their male counterparts. ${ }^{27}$ Other studies have reported poorer survival in females than in males in the United States ${ }^{24}$ and the United Kingdom. ${ }^{28}$ 
The past 20 years have seen considerable improvements in healthcare provision, including improvements in antibiotic and nutrition treatment, and the use of multidisciplinary approaches to management with the formation of specialist treatment centres. We postulated that improvements in healthcare provision will weaken the effect of socioeconomic status and sex on median age at death from cystic fibrosis.

\section{Methods}

We obtained mortality data for cystic fibrosis for England and Wales for 1959 to 2008 from the Office for National Statistics. We used the International Classification of Diseases (ICD) applying to cystic fibrosis to code cause of death. The ICD-9 category for cystic fibrosis was 587.2 in $1959-67,{ }^{29} 273$ in $1968-78,{ }^{30}$ and 277 in $1979-2000 .{ }^{31}$ On publication of ICD-10 in 2001, the category for cystic fibrosis changed to E84. ${ }^{32}$

We classified socioeconomic status using a combination of occupation and employment status. From 1959 to 2000, the Registrar General's Social Class coded socioeconomic status as manual or non-manual. ${ }^{33}$ From 2001, the National Statistics Socioeconomic Classification ${ }^{34}$ classification was used and social class was split into three groups: professional and managerial, intermediate, and routine and manual. For deaths recorded in 1959-78, married women were coded by their husband's socioeconomic class. For deaths recorded from 1979, married women were coded by their own occupation; however, if this was unclassified, their husband's occupation would apply. Throughout the study period, unmarried and single women were coded by their own socioeconomic class when available. Children younger than 16 years were classified by their father's occupation and if their father was not classified, by their mother's occupation. Socioeconomic status for adults was unclassified if individuals were permanently sick, long term unemployed, had never worked, or were in full time education, or if occupation was not stated or described adequately.

To protect anonymity, age at death for each individual was provided by the Office for National Statistics within a five year age range. We estimated age at death as the midpoint of the corresponding five year age band; age at death was not normally distributed for any study year. We estimated median age at death for every study year, and categorised individual deaths as either above or not above the median age for a particular study year. Data were stratified into decades to allow sufficient numbers for statistical comparisons. We included deaths recorded in 1959 in the 1960-69 analysis. Owing to the implementation of the National Statistics Socioeconomic Classification in 2001, we combined deaths in 2000 with deaths in 1990-99 for social class analysis only. Deaths recorded between 1964 and 1969 did not include any socioeconomic data, and we therefore excluded these study years from socioeconomic class analysis.

We calculated the effects of sex and socioeconomic status on the odds ratio for death above the median age at death for every decade by logistic regression using Stata 11 statistical software (Texas, USA). Since both sex and socioeconomic status were associated with the outcome, we mutually adjusted models.

\section{Results}

Between 1959 and 2008, 6750 deaths recorded in England and Wales were attributed to cystic fibrosis. The number of deaths per study year fell during the study period, with a maximum of 214 in 1960 and a minimum of 91 in 2006 (fig $1 \Downarrow$ ).

Median age at death increased from age band 0-4 years to 25-29 years between 1959 and 2008 (fig $2 \Downarrow$ ). From the mid-1970s, median age at death tended to be higher in males than in females (fig $3 \Downarrow$ ). After we adjusted odds ratios for socioeconomic status, males were more likely to die above the median age at death than females in the 1970s and 1980s (table $1 \Downarrow$ ). Overall, the adjusted odds ratio was 1.28 (95\% confidence intervals 1.13 to 1.45) from 1959 to 1999 , and 1.57 (1.18 to 2.08) from 2000 to 2008. Between 2000 and 2008, median age at death was also significantly higher in men (age band 25-29 years) than in women (20-24 years).

Of the 4886 deaths with available social class data between 1959 and 2000, occupation was classified as manual in 2112 (43\%) individuals, non-manual in 1391 (29\%), and unclassified in $1383(28 \%)$. Median age at death was higher in the non-manual group than in the manual group for most study years between 1959 and 2000, and these differences were particularly apparent in the late 1980s and early 1990s (fig $4 \Downarrow$ ). Odds ratios for death above median age at death were significantly lower in the manual group than in the non-manual group at all study time points (table $2 \Downarrow$ ).

For the 873 deaths between 2001 and 2008, socioeconomic status was coded as professional and managerial in $143(16 \%)$ individuals, intermediate in $113(13 \%)$, routine and manual in 175 (20\%), and unclassified in $442(51 \%)$.

After adjusting odds ratios for sex, we found that individuals in the highest socioeconomic class were also more likely to die above the median age of death than those in the lowest socioeconomic class (from 1959 to $2000,2.50,95 \%$ confidence intervals 2.16 to 2.90 ; from 2001 to $2008,1.89,1.20$ to 2.97) (fig 4) (table 2). Median age at death did not differ significantly between the intermediate group and the routine and manual group (table 2). From 2001 to 2008, median age at death was lower in the unclassified group than in the routine and manual group (table 2).

\section{Discussion}

In this cross sectional study of all registered deaths from cystic fibrosis in England and Wales, our data show that the median age at death has increased from 0-4 years in 1959 to 25-29 years in 2008, and that socioeconomic status and sex remain important risk factors for age at death. In addition, despite the overall increase in median age at death from cystic fibrosis, our data consistently show that individuals classified in the highest socioeconomic group are more likely to die at an older age than those in the lowest socioeconomic group. This trend did not change throughout the 50 year study period. Furthermore, health inequalities were not confined to the lowest socioeconomic group. From 2001 to 2008 , median age at death in the intermediate socioeconomic group was comparable to that of the lowest group, with the highest group having a survival advantage. Female disadvantage persisted into the 21 st century, with females having a higher risk of death below the median age of death than males.

\section{Limitations}

The findings of this study depend on the accuracy of the initial diagnosis of cystic fibrosis and satisfactory completion of death certificates including the documentation of a diagnosis of cystic fibrosis. The extent of under-diagnosis of cystic fibrosis in the early years of this study is not clear. In addition, improved diagnostic techniques have led to increased recognition of milder phenotypes which will affect the outcome variable measured. From 1959 to 1967, the International Classification of Diseases category applying to cystic fibrosis included other disease of the pancreas and might therefore include deaths without a 
diagnosis of cystic fibrosis. ${ }^{29}$ However, we have previously estimated that less than $2 \%$ of deaths are probably misclassified in this way, and this proportion is therefore unlikely to affect the overall findings of our study. ${ }^{1}$ The consistency of the associations observed supports this estimate. Furthermore, improved diagnostic techniques in the later study years may have enhanced the recognition of mild phenotypes of cystic fibrosis, which could have contributed to the increased rate of survival observed, although this factor probably does not account for the differences in sex or socioeconomic status.

Due to confidentiality constraints, we used age at death as the midpoint of every five year age band, which could have underestimated the association between socioeconomic status and sex with median age at death. The use of the median age of death was necessary for statistical comparisons between groups, but this is a broad summary statistic that will not reflect a wide spread in ages at death within each year. The data available to us did not provide sufficient power to compare the interaction by study decade of death on the association between age of death and socioeconomic status or sex. However, the similar odds ratios with overlying confidence intervals for the first and last study decades indicate that the magnitude of these associations does not appear to have reduced substantially over time.

We defined socioeconomic status according to occupation from 1959 to 2000 using the Registrar General's Social Class. In 2001, implementation of the internationally recognised and validated ${ }^{35}$ National Statistics Socioeconomic Classification made longitudinal trend comparisons difficult. The availability of socioeconomic status data also varied throughout the study period, with over half of deaths $(51 \%)$ between 2001 and 2008 coded as unclassified, compared with $28 \%$ between 1959 and 2000 (when socioeconomic data were available). Since the definition of unclassified socioeconomic status encompasses a broad cross section of society, such as those adults who were permanently sick, were in long term unemployment, or had never worked to adults in full time education, this represents a limitation of our data.

We saw an increased risk of death above the annual median age of death for the unclassified socioeconomic group from 1959 to 1989; after this time the risk decreased, suggesting that the composition of this group changed over the past half century and possibly reflecting societal change. However, we do not consider that this finding changes the validity of our comparisons between those individuals who could be allocated to a defined social category. We have presented the raw data in two ways, as graphical representations of the annual data and as statistical comparisons of survival by sex and socioeconomic status using data roughly stratified in decades to permit sufficient numbers for comparison. The annual data can show trends over time, although relatively small numbers of events per year prevent conclusions being drawn over short periods of time. Finally, owing to improved survival, the lag time between the implementation of healthcare changes and median age at death is inevitably increasing. Consequently, these results reflect historical healthcare management, and the results of current healthcare strategies, particularly those aimed at younger patients, will not have filtered into the mortality figures yet.

\section{Sex}

Most studies have shown that females are associated with worse outcomes than their male counterparts..$^{24} 27{ }^{28}$ However, the cause of the sex gap remains unclear. Several studies suggest that female preponderance for early acquisition of $P$ aeruginosa might have a role. ${ }^{20}{ }^{26}$ Demko and colleagues ${ }^{20}$ showed that females became infected with chronic mucoid $P$ aeruginos $a$ an average of 1.7 years earlier than their male counterparts. Other studies have suggested that increased occurrence of cystic fibrosis-related diabetes ${ }^{36}$ reduced activity levels, ${ }^{37}$ poor mental health,$^{38}$ poor nutritional status, ${ }^{27}$ and oestrogens ${ }^{39}{ }^{40}$ could contribute to the difference between males and females.

\section{Socioeconomic status}

The association between poor socioeconomic status and increased mortality in individuals with a diagnosis of cystic fibrosis is well established. ${ }^{122}{ }^{23}$ These socioeconomic health disparities have been shown in both the universal healthcare system in the United Kingdom and the predominantly private based care system in the United States. In 1998, Schechter and colleagues $^{41}$ reported that Medicaid patients (a marker of low income in the United States) had worse lung function and lower body mass index and required more hospital admissions than their socioeconomically advantaged counterparts. In 2008, Balmer and colleagues ${ }^{42}$ found that socioeconomically disadvantaged children with cystic fibrosis in the United States had poorer growth, lower lung function, and more days off school than socioeconomically advantaged children. However, the cause of this socioeconomic health gap is poorly understood. Low socioeconomic status has been associated with increased environmental exposure to tobacco smoke, ${ }^{43}$ inadequate nutrition, ${ }^{22}$ little understanding of the underlying disease, ${ }^{44} 45$ and poor treatment adherence. ${ }^{41}$

It is difficult to determine what role these individual factors have because social class is a composite measure that incorporates income, education, and occupation. It is clear, however, that socioeconomic status may affect childhood health from an early age. Phenotypical differences between high and low socioeconomic groups have been found in children with cystic fibrosis as young as 6 years, and these disparities persist into adulthood. ${ }^{23}{ }^{41}$ However, reverse causation could complicate the association between low socioeconomic status and increased mortality. Individuals with cystic fibrosis are more likely to leave school without any qualifications than the general population and therefore less likely to have professional occupations, and this difference is increased in individuals with severe underlying disease. ${ }^{46}$ Conversely, individuals with cystic fibrosis who are in employment are more likely to have non-manual occupations than the general population, ${ }^{46}$ perhaps because they are less able to fulfil more physically demanding work. Since our data from recent years cover deaths in a mainly adult population, we cannot exclude the possibility that these factors might contribute to our observations of differences in mortality between socioeconomic groups.

\section{Provision of care}

Over the past few decades, increasing awareness of the complexity of cystic fibrosis disease management has led to the formation of specialist centralised centres. Specialist treatment centres are widely considered to provide the best standard care for patients ${ }^{13} 474$ and are endorsed by regulatory bodies in the United Kingdom, ${ }^{49}{ }^{50}$ United States, ${ }^{51}{ }^{52}$ and Australia. ${ }^{53}$ Consequently, the proportion of patients accessing specialist care has risen over the past 20 years. ${ }^{54}$ However, direct evidence supporting improved clinical outcomes in specialist cystic fibrosis centres is limited and most studies have been confounded by sample size ${ }^{6567}$ or by comparison with historical controls. ${ }^{58}$ Mahadeva and colleagues ${ }^{47}$ reported that patients who attended specialist centres in Manchester had higher body mass indexes, higher chest radiograph scores, and better 
pulmonary function than patients in Cambridge who did not receive any centralised care. However, direct comparisons between different regions may be confounded by environmental factors $^{59}$ and socioeconomic status. ${ }^{1}$

Inequalities in access to specialist cystic fibrosis services have shown marked regional variations. ${ }^{4}$ Patients receiving care at specialist centres generally travel further than those attending local clinics and, although not a universal finding, ${ }^{23} 4160$ some studies have shown that socioeconomically disadvantaged individuals have limited access to specialist care, particularly to adult services, ${ }^{4}{ }^{61}$ in the United Kingdom. Accordingly, the proportion of patients from socioeconomically advantaged backgrounds is over-represented at some specialist centres. ${ }^{61}$

A possible interpretation of our data is that new specialist treatment centres in the United Kingdom might have been preferentially accessed by individuals with the highest socioeconomic status, which could account for some of the socioeconomic discrepancy seen during the late 1980s and early 1990s. Alternatively, the highest socioeconomic groups could be better informed and hence obtain better healthcare when attending clinic. The observation by Schechter and colleagues ${ }^{60}$ that children living in affluent areas or with well educated mothers were more likely to receive macrolides in 2004, one year after a landmark study was published, ${ }^{62}$ would support the latter hypothesis. Our data also showed that individuals in the unclassified socioeconomic group had a poorer outcome than any other category over the past two decades. This heterogeneous category included individuals who were permanently sick, long term unemployed, or receiving incapacity benefits. The severity of the underlying disease and reverse causation could have been contributing factors. However, this category might represent the lowest socioeconomic group in society, including individuals who struggle to access timely healthcare.

\section{Summary}

We report nationally representative data that suggest that the socioeconomic and sex differences in age at death from cystic fibrosis that we first reported in 1989 persist to the present day, in the context of a large improvement in survival in this patient group over the past half century. Healthcare workers should be aware that females and low socioeconomic status are associated with poorer outcomes than males and high socioeconomic status. Environmental factors or varying access to healthcare might account for some of these differences.

We thank Brian Johnson from the Office for National Statistics for supplying the data.

Contributors: HLB contributed to the acquisition of data, statistical analysis and interpretation of data, drafting the article, and final approval of the version to be published. JB contributed to the concept and design of the study, interpretation of the data, drafting the article, and final approval of the version to be published. ARS contributed to the interpretation of the data, drafting the article, and final approval of the version to be published. AWF contributed to the concept and design of the study, acquisition of data, statistical analysis and interpretation of data, drafting the article, and approval of the final version to be published. AWF is the data guarantor.

Funding: This research was funded by the Medical Research Council and the University of Nottingham.

Competing interests: All authors have completed the ICMJE uniform disclosure form at www.icmje.org/coi_disclosure.pdf (available on request from the corresponding author) and declare: no support from any organisation for the submitted work; no financial relationships with any organisations that might have an interest in the submitted work in the previous three years; no other relationships or activities that could appear to have influenced the submitted work.

1 Britton JR. Effects of social class, sex, and region of residence on age at death from cystic fibrosis. BMJ 1989;298:483-7.

2 Cystic Fibrosis Trust. UK CF registry annual report, 2008. Cystic Fibrosis Trust, 2008.

3 Elborn JS, Shale DJ, Britton JR. Cystic fibrosis: current survival and population estimates to the year 2000. Thorax 1991;46:881-5.

4 Walters S, Britton J, Hodson ME. Hospital care for adults with cystic fibrosis: an overview and comparison between special cystic fibrosis clinics and general clinics using a patien questionnaire. Thorax 1994;49:300-6.

5 Dodge JA, Lewis PA, Stanton M, Wilsher J. Cystic fibrosis mortality and survival in the UK: 1947-2003. Eur Respir J 2007;29:522-6.

6 Merelle ME, Schouten JP, Gerritsen J, Dankert-Roelse JE. Influence of neonatal screening and centralized treatment on long-term clinical outcome and survival of CF patients. Eur Respir J 2001;18:306-15.

7 Farrell PM, Lai HJ, Li Z, Kosorok MR, Laxova A, Green CG, et al. Evidence on improved outcomes with early diagnosis of cystic fibrosis through neonatal screening: enough is enough! J Pediatr 2005;147(suppl 3):S30-6.

8 Corey M, McLaughlin FJ, Williams M, Levison H. A comparison of survival, growth, and pulmonary function in patients with cystic fibrosis in Boston and Toronto. J Clin Epidemio 1988;41:583-91.

9 Cheng K, Smyth RL, Govan JR, Doherty C, Winstanley C, Denning N, et al. Spread of beta-lactam-resistant Pseudomonas aeruginosa in a cystic fibrosis clinic. Lancet 1996;348:639-42.

10 Jones AM, Govan JR, Doherty CJ, Dodd ME, Isalska BJ, Stanbridge TN, et al. Spread of a multiresistant strain of Pseudomonas aeruginosa in an adult cystic fibrosis clinic. Lancet 2001;358:557-8.

11 Armstrong D, Bell S, Robinson M, Bye P, Rose B, Harbour C, et al. Evidence for spread of a clonal strain of Pseudomonas aeruginosa among cystic fibrosis clinics. J Clin Microbiol 2003:41:2266-7.

12 George PM, Banya W, Pareek N, Bilton D, Cullinan P, Hodson ME, et al. Improved survival at low lung function in cystic fibrosis: cohort study from 1990 to 2007. BMJ 2011;342:d1008

13 Frederiksen B, Lanng S, Koch C, Hoiby N. Improved survival in the Danish center-treated cystic fibrosis patients: results of aggressive treatment. Pediatr Pulmonol 1996;21:153-8.

14 Valerius NH, Koch C, Hoiby N. Prevention of chronic Pseudomonas aeruginosa colonisation in cystic fibrosis by early treatment. Lancet 1991;338:725-6.

15 Johansen HK, Nir M, Hoiby N, Koch C, Schwartz M. Severity of cystic fibrosis in patients homozygous and heterozygous for delta F508 mutation. Lancet 1991;337:631-4.

16 Schaedel C, Monestrol I, Hjelte L, Johannesson M, Kornfält R, Lindblad A, et al. Predictors of deterioration of lung function in cystic fibrosis. Pediatr Pulmonol 2002;33:483-91.

17 Corey M, Edwards L, Levison $\mathrm{H}$, Knowles M. Longitudinal analysis of pulmonary function decline in patients with cystic fibrosis. J Pediatr 1997;131:809-14.

18 Huang NN, Schidlow DV, Szatrowski TH, Palmer J, Laraya-Cuasay LR, Yeung W, et al. Clinical features, survival rate, and prognostic factors in young adults with cystic fibrosis. Am J Med 1987;82:871-9.

19 Emerson J, Rosenfeld M, McNamara S, Ramsey B, Gibson RL. Pseudomonas aeruginosa and other predictors of mortality and morbidity in young children with cystic fibrosis. Pediatr Pulmonol 2002;34:91-100

20 Demko CA, Byard PJ, Davis PB. Gender differences in cystic fibrosis: Pseudomonas aeruginosa infection. J Clin Epidemiol 1995;48:1041-9.

21 Henry RL, Mellis CM, Petrovic L. Mucoid Pseudomonas aeruginosa is a marker of poor survival in cystic fibrosis. Pediatr Pulmonol 1992;12:158-61.

22 Schechter MS, Shelton BJ, Margolis PA, Fitzsimmons SC. The association of socioeconomic status with outcomes in cystic fibrosis patients in the United States. Am $J$ Respir Crit Care Med 2001;163:1331-7.

23 O'Connor GT, Quinton HB, Kneeland T, Kahn R, Lever T, Maddock J, et al. Media household income and mortality rate in cystic fibrosis. Pediatrics 2003;111:e333-9.

24 FitzSimmons SC. The changing epidemiology of cystic fibrosis. J Pediatr 1993;122:1-9.

25 Dodge JA, Morison S, Lewis PA, Colest EC, Geddes D, Russell G, et al. Cystic fibrosis in the United Kingdom, 1968-1988: incidence, population and survival. Paediatr Perinat Epidemiol 1993;7:157-66.

26 Rosenfeld M, Davis R, FitzSimmons S, Pepe M, Ramsey B. Gender gap in cystic fibrosis mortality. Am J Epidemiol 1997; 145:794-803.

27 Kerem E, Reisman J, Corey M, Canny GJ, Levison H. Prediction of mortality in patients with cystic fibrosis. N Engl J Med 1992;326:1187-91.

28 British Paediatric Association Working Party on Cystic Fibrosis. Cystic fibrosis in the United Kingdom 1977-85: an improving picture. BMJ 1988;297:1599-602.

29 World Health Organization. Manual of international statistical classification of diseases, injuries and causes of death. 7th ed.WHO, 1957.

30 World Health Organization. Manual of the international statistical classification of diseases, injuries and causes of death. 8th ed.WHO, 1965.

31 World Health Organization. Manual of the international statistical classification of diseases, injuries and causes of death. 9th ed. WHO, 1975.

32 World Health Organization. International statistical classification of diseases and related health problems. 10th revision (ICD-10).WHO, 1994

33 OPCS. Classification of occupations. HMSO, 1966.

34 Rose D, O'Reilly, K. The ESRC review of government social classifications: final report. The Stationery Office, 1998.

35 Rose D, Prevalin DJ, eds. A researcher's guide to the national statistics socio-economic classification. Sage Publications, 2003.

36 Adler AI, Shine BS, Chamnan P, Haworth CS, Bilton D. Genetic determinants and epidemiology of cystic fibrosis-related diabetes: results from a British cohort of children and adults. Diabetes Care 2008:31:1789-94.

37 Selvadurai HC, Blimkie CJ, Cooper PJ, Mellis CM, Van Asperen PP. Gender differences in habitual activity in children with cystic fibrosis. Arch Dis Child 2004;89:928-33.

38 Arrington-Sanders R, Yi MS, Tsevat J, Wilmott RW, Mrus JM, Britto MT. Gender differences in health-related quality of life of adolescents with cystic fibrosis. Health Qual Life Outcomes 2006;4:5. 


\section{What is already known on this topic}

Survival in individuals diagnosed with cystic fibrosis has improved greatly over the past 50 years, with the median age of death increasing from 6 months to 27 years

In the late 20th century, survival improved most in males and socioeconomically advantaged individuals

\section{What this study adds}

Despite overall improved survival in the 21 st century, females and socioeconomically disadvantaged individuals continue to be more likely to die below the median age of death than males and socioeconomically advantaged individuals

39 Coakley RD, Sun H, Clunes LA, Rasmussen JE, Stackhouse JR, Okada SF, et al. 17beta-Estradiol inhibits $\mathrm{Ca} 2+$-dependent homeostasis of airway surface liquid volume in human cystic fibrosis airway epithelia. $J$ Clin Invest 2008;118:4025-35.

40 Zeitlin PL. Cystic fibrosis and estrogens: a perfect storm. J Clin Invest 2008;118:3841-4.

41 Schechter MS, Margolis PA. Relationship between socioeconomic status and disease severity in cystic fibrosis. J Pediatr 1998;132:260-4.

42 Balmer DF, Schall JI, Stallings VA. Social disadvantage predicts growth outcomes in preadolescent children with cystic fibrosis. J Cyst Fibros 2008;7:543-50.

43 Rubin BK. Exposure of children with cystic fibrosis to environmental tobacco smoke. $N$ Engl J Med 1990;323:782-8.

44 Nolan T, Desmond K, Herlich R, Hardy S. Knowledge of cystic fibrosis in patients and their parents. Pediatrics 1986;77:229-35.

45 Henley LD, Hill ID. Errors, gaps, and misconceptions in the disease-related knowledge of cystic fibrosis patients and their families. Pediatrics 1990;85:1008-14.

46 Walters S, Britton J, Hodson ME. Demographic and social characteristics of adults with cystic fibrosis in the United Kingdom. BMJ 1993;306:549-52.

47 Mahadeva R, Webb K, Westerbeek RC, Carroll NR, Dodd ME, Bilton D, et al. Clinical outcome in relation to care in centres specialising in cystic fibrosis: cross sectional study. BMJ 1998;316:1771-5.

48 Phelan P, Hey E. Cystic fibrosis mortality in England and Wales and in Victoria, Australia 1976-80. Arch Dis Child 1984;59:71-3.

49 Royal College of Physicians. Cystic fibrosis in adults. Recommendations for care of patients in the UK. Summary of a report of the Royal College of Physicians. J R Coll Physicians Lond 1991;25:12-5.

50 Jackson A. Clinical guidelines for cystic fibrosis care. Summary of guidelines prepared by a working group of the Cystic Fibrosis Trust, the British Paediatric Association, and the British Thoracic Society. J R Coll Physicians Lond 1996;30:305-8.

51 Borowitz D, Robinson KA, Rosenfeld M, Davis SD, Sabadosa KA, Spear SL, et al. Cystic Fibrosis Foundation evidence-based guidelines for management of infants with cystic fibrosis. J Pediatr 2009;155(suppl 6):S73-93.

52 Yankaskas JR, Marshall BC, Sufian B, Simon RH, Rodman D. Cystic fibrosis adult care: consensus conference report. Chest 2004;125(suppl 1):1-39S.

53 Bell SC. Cystic fibrosis standards of care. Cystic Fibrosis Australia, 2008.
54 Walters $S$. National health services for patients with cystic fibrosis: the good, the bad and the ugly. J R Soc Med 2002;95(suppl 41):32-40.

55 Elborn JS, Hodson M, Bertram C. Implementation of European standards of care for cystic fibrosis-provision of care. J Cyst Fibros 2009;8:348-55.

56 Collins CE, MacDonald-Wicks L, Rowe S, O'Loughlin EV, Henry RL. Normal growth in cystic fibrosis associated with a specialised centre. Arch Dis Child 1999;81:241-6.

57 Van Koolwijk LM, van der Laag J, Hockstra JH, Gulmans VA, van der Ent CK. Treatment of children with cystic fibrosis: central, local or both? Acta Paediatr 2002;91:972-7.

58 Hill DJ, Martin AJ, Davidson GP, Smith GS. Survival of cystic fibrosis patients in South Australia. Evidence that cystic fibrosis centre care leads to better survival. Med J Aust 1985;143:230-2.

59 Lebecque P, Leonard A, De Boeck K, De Baets F, Malfroot A, Casimir G, et al. Early referral to cystic fibrosis specialist centre impacts on respiratory outcome. J Cyst Fibros 2009;8:26-30.

60 Schechter MS, McColley SA, Silva S, Haselkorn T, Konstan MW, Wagener JS. Association of socioeconomic status with the use of chronic therapies and healthcare utilization in children with cystic fibrosis. J Pediatr 2009;155:634-9,e1-4.

61 Penketh AR, Wise A, Mearns MB, Hodson ME, Batten JC. Cystic fibrosis in adolescents and adults. Thorax 1987;42:526-32.

62 Saiman L, Marshall BC, Mayer-Hamblett N, Burns JL, Quittner AL, Cibene DA, et al. Azithromycin in patients with cystic fibrosis chronically infected with Pseudomonas aeruginosa : a randomized controlled trial. JAMA 2003;290:1749-56.

\section{Accepted: 22 June 2011}

\section{Cite this as: BMJ 2011;343:d4662}

This is an open-access article distributed under the terms of the Creative Commons Attribution Non-commercial License, which permits use, distribution, and reproduction in any medium, provided the original work is properly cited, the use is non commercial and is otherwise in compliance with the license. See: http://creativecommons.org/licenses/by$\mathrm{nc} / 2.0 /$ and http://creativecommons.org/licenses/by-nc/2.0/legalcode. 


\section{Tables}

Table 1| Association of sex with risk of death at age greater than median age at death from cystic fibrosis in England and Wales, 1959-2008 Male deaths at age greater than median age at death

Study year Total number of deaths Female deaths (odds ratio) Unadjusted odds ratio (95\% Cl) Adjusted* odds ratio (95\% $\left.\mathrm{Cl}^{*}\right)$

\begin{tabular}{lllll}
$1959-69$ & 1960 & 1.00 & $1.05(0.87$ to 1.27$)$ & $0.99(0.74$ to 1.33$)$ \\
\hline $1970-79$ & 1425 & 1.00 & $1.48(1.19$ to 1.84$)$ & $1.55(1.22$ to 1.97$)$ \\
\hline $1980-89$ & 1215 & 1.00 & $1.31(1.04$ to 1.65$)$ & $1.35(1.06$ to 1.72$)$ \\
\hline $1990-99$ & 1172 & 1.00 & $1.19(0.94$ to 1.51$)$ & $1.25(0.98$ to 1.60$)$ \\
\hline $2000-08$ & 978 & 1.00 & $1.44(1.10$ to 1.87$)$ & $1.57(1.18$ to 2.08$)$ \\
\hline
\end{tabular}

$95 \% \mathrm{Cl}=95 \%$ confidence intervals.

${ }^{*}$ Adjusted for socioeconomic status. 
Table 2 | Association of socioeconomic status with risk of death at age greater than median age at death from cystic fibrosis in England and Wales, 1959-2008

\begin{tabular}{|c|c|c|c|c|c|c|c|c|}
\hline \multirow[b]{2}{*}{ Study year } & \multirow{2}{*}{$\begin{array}{c}\text { Total } \\
\text { number of } \\
\text { deaths }\end{array}$} & \multicolumn{7}{|c|}{ Risk of death at age greater than median age at death, by socioeconomic status } \\
\hline & & Manual & Non-manual ${ }^{*}$ & Unclassified ${ }^{*}$ & $\begin{array}{l}\text { Routine and } \\
\text { manual }\end{array}$ & Intermediate ${ }^{*}$ & $\begin{array}{l}\text { Professional and } \\
\text { managerial }^{\star}\end{array}$ & Unclassified ${ }^{\star}$ \\
\hline $1959-63 \dagger$ & 969 & 1.00 & 1.90 (1.35 to 2.67$)$ & 3.55 (2.36 to 5.33$)$ & - & - & - & - \\
\hline $1970-79$ & 1425 & 1.00 & 2.05 (1.57 to 2.69$)$ & $11.33(8.24$ to 15.58$)$ & - & - & - & - \\
\hline 1980-89 & 1215 & 1.00 & $3.04(2.26$ to 4.10$)$ & 3.39 (2.52 to 4.56$)$ & - & - & - & - \\
\hline $1990-2000$ & 1277 & 1.00 & 2.06 (1.52 to 2.80$)$ & 0.56 (0.41 to 0.76$)$ & - & - & - & - \\
\hline 2001-08‡ & 873 & - & - & - & 1.00 & $\begin{array}{c}1.07(0.66 \text { to } \\
1.72)\end{array}$ & 1.89 (1.20 to 2.97$)$ & $\begin{array}{c}0.30(0.21 \text { to } \\
0.44)\end{array}$ \\
\hline
\end{tabular}

Data are odds ratio or adjusted odds ratio (95\% confidence intervals) unless stated otherwise.

*Odds ratios adjusted for sex.

†Socioeconomic status not classified in 1964-69.

¥Socioeconomic status coding changed after 2000. 
BMJ 2011;343:d4662 dol: 10.1136/bmj.d4662

Page 8 of 9

RESEARCH

Figures

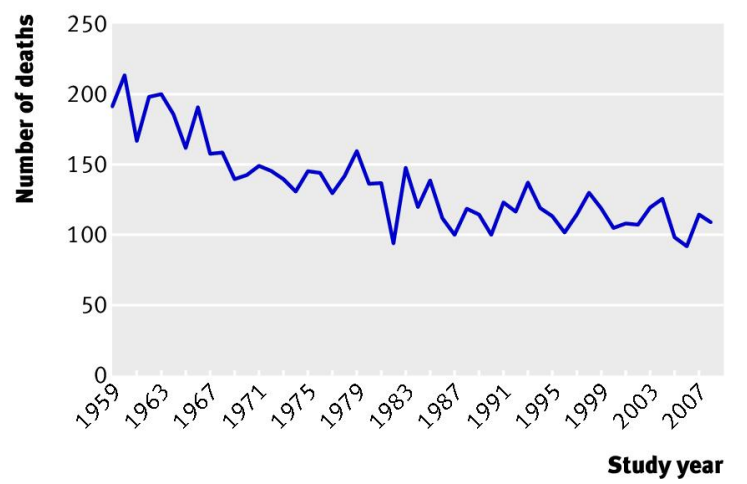

Fig 1 Estimated number of deaths from cystic fibrosis in England and Wales, 1959-2008

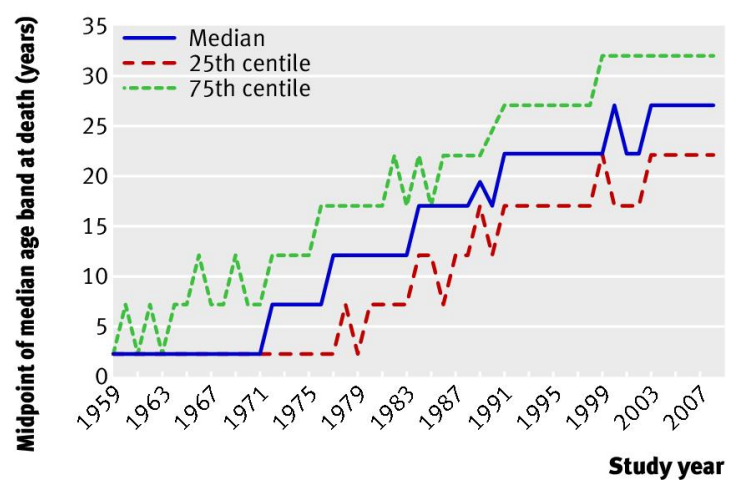

Fig 2 Median age at death from cystic fibrosis in England and Wales, 1959-2008

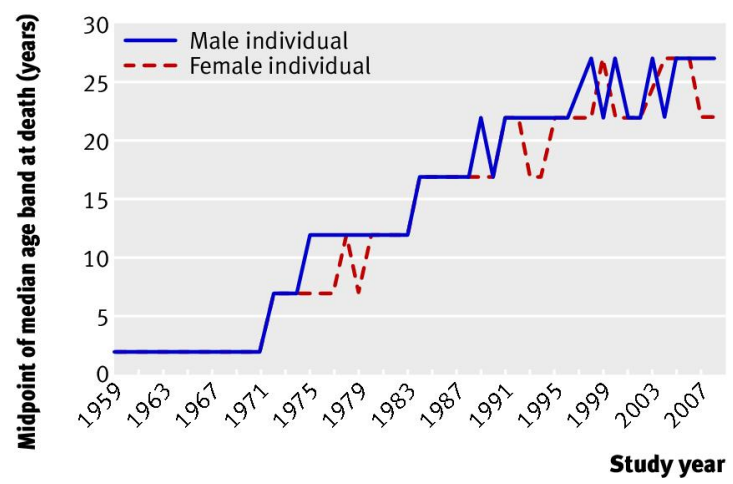

Fig 3 Median age at death with diagnosis of cystic fibrosis by sex in England and Wales, 1959-2008

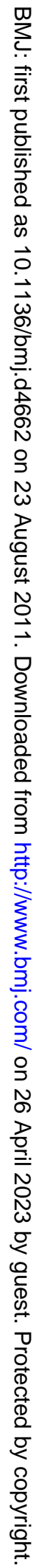

No commercial reuse: See rights and reprints http://www.bmj.com/permissions

Subscribe: http://www.bmj.com/subscribe 


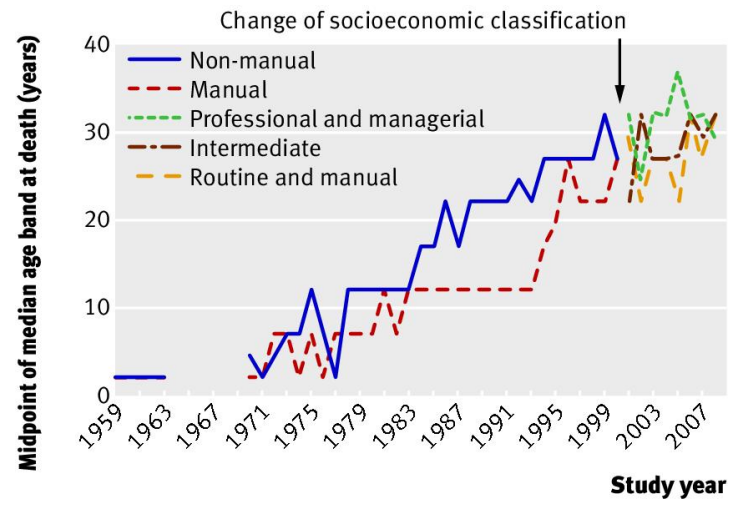

Fig 4 Median age at death with diagnosis of cystic fibrosis by socioeconomic status in England and Wales, 1959-2008 